\title{
A Review of the Cytomorphology of Epstein-Barr Virus-Associated Malignancies
}

\author{
Pam Michelow $^{\mathrm{a}}$ Colleen Wright $^{\mathrm{b}}$ Liron Pantanowitz ${ }^{\mathrm{c}}$

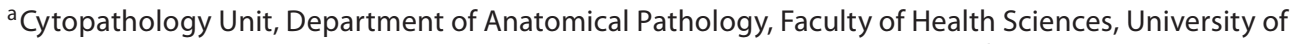 \\ Witwatersrand and National Health Laboratory Services, Johannesburg, and ${ }^{b}$ Division of Anatomical Pathology, \\ Department of Pathology, Stellenbosch University and National Health Laboratory Services, Cape Town,

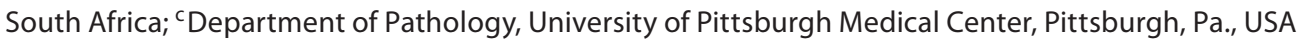

\section{Key Words}

Epstein-Barr virus $\cdot$ Hodgkin lymphoma $\cdot$ Carcinoma $•$

Tumor · Posttransplant lymphoproliferative disorder a diagnosis of EBV-associated malignancy. This review discusses the unique cytomorphology and ancillary studies required to diagnose EBV-related neoplasms.

Copyright $\odot 2012$ S. Karger AG, Basel

\begin{abstract}
The Epstein-Barr virus (EBV) is a member of the herpes family of viruses and is very common in humans. EBV is most often associated with infectious mononucleosis. However, it is estimated that $1 \%$ of tumors including lymphoproliferative, epithelial and mesenchymal are linked to EBV infection. EBV has a tropism for certain epithelial cells, lymphocytes and myocytes. Like other herpesviruses, EBV has both lytic and latent phases of infection. In the latent form, EBV-encoded genes ensure the survival of the viral genome, allowing it to circumvent the host's immune surveillance by limited expression of viral proteins and carries with it the risk of neoplastic transformation. Cytologists are likely to encounter EBV-associated malignancies in cytology material but unlike other herpesviruses, EBV does not evoke a viral cytopathic effect. The manifestation of EBV-related tumors is also often variable depending upon the patient's immune status. Therefore, knowledge of the patient's EBV status and immune competence (e.g. HIV-infection or transplant-related immunosuppression) combined with the cytomorphology and results of ancillary studies are often all required to make
\end{abstract}

\section{Introduction}

The Epstein-Barr virus (EBV) is part of the gamma herpes family of viruses and is also known as human herpesvirus 4 (HHV-4). This double-stranded DNA virus is ubiquitous and one of the most common viruses occurring in humans. It is associated with a wide spectrum of benign and malignant conditions, the most well-known being infectious mononucleosis $[1,2]$ and is linked with $1 \%$ of tumors globally [3]. It is related to the development of diverse lymphoproliferative, epithelial and mesenchymal neoplasms $[1,2,4-10]$. It was the first virus to be associated with human cancer, namely, Burkitt lymphoma, by the identification of the EBV virion on electron microscopy in a cultured cell line of African Burkitt lymphoma [11].

Presented in part at the 1st Laboratory Medicine Congress, Johannesburg, South Africa, 1-4 September, 2011.

\section{KARGER}

Fax +41613061234 E-Mail karger@karger.ch www.karger.com
(C) 2012 S. Karger AG, Basel

0001-5547/12/0561-0001\$38.00/0

Accessible online at:

www.karger.com/acy
Correspondence to: Dr. Pam Michelow

Cytopathology Unit, Department of Anatomical Pathology

Faculty of Health Sciences, University of Witwatersrand and NHLS

PO Box 1038, Johannesburg 2000 (South Africa)

Tel. +27 1148 99402, E-Mail pamela.michelow@nhls.ac.za 
Table 1. Patterns of latent gene expression in EBV [12]

\begin{tabular}{|c|c|c|c|c|c|c|}
\hline \multirow[t]{2}{*}{ EBV gene } & \multirow{2}{*}{$\begin{array}{l}\text { Acute } \\
\text { infec- } \\
\text { tion }\end{array}$} & \multirow{2}{*}{$\begin{array}{l}\text { Latency I } \\
\text { Burkitt } \\
\text { lymphoma }\end{array}$} & \multicolumn{2}{|l|}{ Latency II } & \multicolumn{2}{|c|}{ Latency III } \\
\hline & & & $\begin{array}{l}\text { Hodgkin } \\
\text { lymphoma }\end{array}$ & NPC & PCNSL & PTLD \\
\hline EBNA-1 & + & + & + & + & + & + \\
\hline EBNA-2 & + & - & - & - & + & + \\
\hline EBNA-3 & + & - & - & - & + & + \\
\hline LMP-1 & + & - & + & + & + & + \\
\hline LMP-2 & + & - & + & + & + & + \\
\hline EBER & + & + & + & + & + & + \\
\hline
\end{tabular}

$\mathrm{NPC}=$ Nasopharyngeal carcinoma; PCNSL $=$ primary central nervous system lymphoma; PTLD = post-transplant lymphoproliferative disorder.

\section{Viral Oncogenesis}

EBV has a tropism for epithelial cells (e.g. oral and nasopharyngeal mucosa), lymphocytes (B and T cells) and myocytes. Like other herpesviruses, it has both a latent phase of infection and a lytic (productive) phase that produces new infectious virions. Primary infection may cause infectious mononucleosis, but most infections are initially asymptomatic. Infected B cells activate T cells, the cause of atypical lymphocytosis in infectious mononucleosis. In the latent form, EBV-encoded genes ensure the survival of the viral genome, allowing it to circumvent the host's immune surveillance by limited expression of viral proteins and carry with it the risk of neoplastic transformation. Latent infection in cells is characterized by the expression of latent membrane proteins (LMP) 1 and 2, EBV nuclear antigens (EBNAs) and EBVencoded RNAs (EBERs) [4-7]. The EBERs are highly transcribed in latent infection, often with more than $10^{6}$ copies/infected cell localized in the nucleus $[1,5-10]$. EBV-associated malignancies are associated with latent gene expression (table 1). In an immunocompetent host, persistent EBV infection is kept in check, which is why the vast majority of the population never develops EBVassociated tumors. Cofactors that may play a role in the development of EBV-associated neoplasms include genetic susceptibility, environmental factors like parasitic infections (e.g. malaria), nutritional issues (e.g. malnutrition and consumption of food with possible carcinogens like volatile nitrosamines) and reactivation related to the host's immune status (e.g. HIV-infection and transplant patients) $[1,2,4-11]$. In many of the malignancies described in this review, the presence of EBV in a clonal episomal form within tumor cells indicates that this virus entered these cells prior to their clonal expansion. EBVinfected tumor cells frequently evoke a marked host immune response, such that the neoplastic cells (e.g. ReedSternberg cells in Hodgkin lymphoma or carcinoma cells in lymphoepithelial-like carcinoma) are often masked by the background benign lymphoid component [1, 2, 4-11].

Cytologists are likely to encounter EBV-associated malignancies in cytology material. However, unlike other herpesviruses, EBV does not evoke a viral cytopathic effect. The manifestation of EBV-related tumors is often also variable depending upon the patient's immune status. Therefore, knowledge of the patient's EBV status and immune competence (e.g. HIV-infection- or transplantrelated immunosuppression) combined with the cytomorphology and results of ancillary studies are often all required to make a diagnosis of EBV-associated malignancy [12]. This review discusses the unique cytomorphology and ancillary studies required to diagnose EBVrelated neoplasms.

\section{Ancillary Studies}

There are various methods to determine the presence of EBV infection. In the host, these include serological tests (e.g. the heterophile antibody or 'monospot' test), enzyme-linked immunosorbent assays (ELISA) and EBV viral-load assays which help distinguish a healthy carrier from one in the disease state [7, 9]. EBV viral-load assays have been used in the management of posttransplant lymphoproliferative disorder (PTLD) and nasopharyngeal carcinoma, whereby EBV DNA levels in plasma or serum determine response to therapy; high levels prior to therapy carry a worse prognosis and test recurrence [7]. Within tumors, EBV infection can be demonstrated using commercially existing antibodies against EBNAs (detected by immunofluorescence) and LMP-1 (by membranous and cytoplasmic immunohistochemical staining), RNA in situ hybridization to detect EBERs and/or molecular studies such as Southern blot hybridization and polymerase chain reaction (PCR) [13]. The identification of EBV in neoplastic cells can be very helpful in the diagnosis of certain tumors [e.g. nasopharygeal carcinoma and primary central nervous system lymphoma (PCNSL)] and in differentiating posttransplant lymphoproliferative disorder from a rejection. In situ hybridization for EBER is perhaps the best test for detecting and localizing latent EBV in tissue and cytology samples $[10,14,15]$. False-positive EBER interpretations may occur as a result of confusion regarding the latent infection of background 
Fig. 1. a A classic Reed-Sternberg cell present in a background of small lymphocytes. Papanicolaou stain, $\times 600$. b CD30 membranous and focal paranuclear dot-like immunoreactivity of Reed-Sternberg cells is shown in cell block material from an FNA of an axillary lymph node involved by classic Hodgkin lymphoma. $\times 400$.
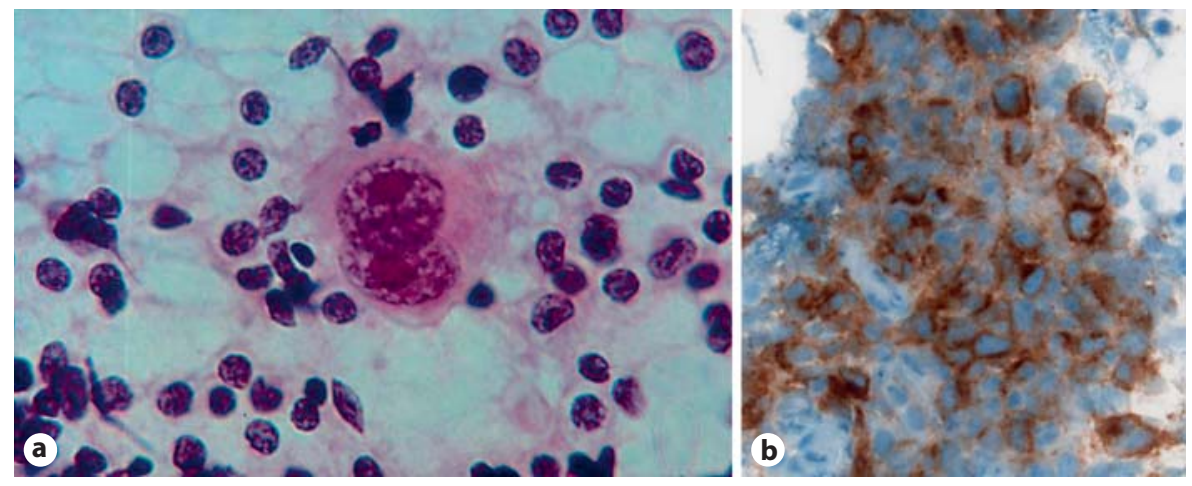

lymphocytes instead of lymphoma cells, nonspecific staining or cross-reactivity with mucin, yeast or plant materials. False-negative results may occur with RNA degradation, therefore an appropriate RNA control should be examined when interpreting an EBER in situ hybridization test [12].

\section{Lymphoproliferative Disorders}

EBV is associated with several lymphoproliferative disorders including Hodgkin lymphoma and $\mathrm{B}$ and $\mathrm{T}$ cell non-Hodgkin lymphomas. EBV-associated B cell lymphomas include Burkitt lymphoma, PTLD, lymphomatoid granulomatosis, pyothorax-associated lymphoma and EBV-associated B cell lymphoma of the elderly $[4,5]$. In HIV-infected patients, EBV is associated with PCNSL, primary effusion lymphoma (PEL) and plasmablastic lymphoma (PBL) [4-10].

\section{Hodgkin Lymphoma}

There is a bimodal incidence of Hodgkin lymphoma (formerly called Hodgkin's disease) affecting both young people in adolescence to early adulthood as well as those in their 70s. There is an increased incidence in HIV-positive and transplant patients. The presentation of Hodgkin lymphoma includes B symptoms (fever, night sweats and weight loss), lymphadenopathy (cervical, mediastinal and axillary), and extranodal disease (e.g. hepatosplenomegaly). EBV is more commonly associated with classic Hodgkin lymphoma, especially the mixed cellularity subtype; it is hardly ever associated with the nodular lymphocyte-predominant subtype $[4,5,10]$. Not all histologic subtypes of Hodgkin lymphoma (nodular sclerosis, mixed-cellularity, lymphocyte-rich and lymphocyte-depleted) may be reliably identified by FNA. How- ever, from a clinical management point of view, it is only really necessary to differentiate classic Hodgkin lymphoma from nodular lymphocyte predominant Hodgkin lymphoma, and this can often be performed using immunocytochemistry on the FNA specimen [16].

Aspirates may be hypo- or hyper-cellular depending on the amount of associated sclerosis. Classic Hodgkin lymphoma is characterized by the presence of a minority of neoplastic cells (Reed-Sternberg cells and their variants) in an inflammatory background. Background inflammatory cells consist of varying numbers of small lymphocytes, plasma cells, neutrophils, eosinophils and macrophages, including epithelioid histiocytes $[17,18]$. In EBV-associated cases, histiocytes may exhibit prominent epithelioid features and may form granulomas. Necrosis is rare. The classic Reed-Sternberg cell is a binucleate cell whereby the two nuclei are mirror images of each other. The nuclei are enlarged with pale, finely granular chromatin, prominent red macronucleoli and a moderate amount of cytoplasm (fig. 1). Mononuclear variants of Reed-Sternberg cells (called 'Hodgkin cells') have a large, irregular or polylobated nucleus with a very prominent, single red macronucleolus. The 'lymphocytic and histiocytic' variants, sometimes referred to as 'popcorn cells', have vesicular, polylobulated nuclei and distinct, small, usually peripheral nucleoli without perinucleolar halos $[17,18]$. In classic Hodgkin lymphoma Reed-Sternberg cells are positive for CD15 and CD30 (usually a membrane-pattern staining with paranuclear dot-like Golgi accentuation), with CD20 and EMA showing positivity in a small number of cells (table 2). Reed-Sternberg cells express LMP (LMP-1), EBNA (EBNA-1) and EBER (EBER-1) [5-10]. Flow cytometry and molecular studies are not usually helpful. The differential diagnosis includes benign reactive lymphadenopathy of various etiologies, including infectious mononucleosis, large cell 
Table 2. Immunophenotypic features of Hodgkin lymphoma

\begin{tabular}{lll}
\hline & Classic Hodgkin lymphoma & NLPHL \\
\hline Tumor cells & RS cells and mononuclear (Hodgkin) cells & L and H (popcorn) cells \\
\hline Background cells & lymphocytes (T>B cells), plasma cells, & lymphocytes (B>T cells), histiocytes \\
& eosinophils, neutrophils, histiocytes & \\
\hline Fibrosis & common & rare \\
CD45 (LCA) & - & + \\
CD20 & $+/-$ & + \\
CD15 & + & - \\
CD30 & + & - \\
EMA & - & $+/-$ \\
PAX5 & $+($ weak) & $+($ weak) \\
OCT-2 & $+/-$ & + \\
BOB- & $+/-$ & + \\
Fascin & $+/-$ & + \\
EBV (in RS cells) & $+(50 \%$ RS cells) & - \\
\hline
\end{tabular}

L and $\mathrm{H}=$ Lymphocytic and histiocytic; LCA = leukocyte common antigen; NLPHL = nodular lymphocyte predominant Hodgkin lymphoma; RS = Reed-Sternberg.

lymphomas [anaplastic large cell lymphoma, diffuse large B cell lymphoma (DLBCL), T-cell-rich B cell lymphoma], carcinoma (nasopharyngeal carcinoma), seminoma and melanoma [19-21].

\section{Burkitt Lymphoma}

Burkitt lymphoma is a very rapid-growing, high-grade B cell non-Hodgkin lymphoma that primarily presents in extranodal sites. Three separate clinical variants of Burkitt lymphoma can be identified: endemic, sporadic and immunodeficiency-associated. The endemic type often involves the jaw and facial bones and is most commonly found in equatorial African and Asian children. EBV has been documented in virtually all endemic cases of Burkitt lymphoma. The pathogenesis of endemic Burkitt lymphoma is partly attributed to impaired immune competence accompanying chronic malaria infection. The sporadic type, with a distribution worldwide, often presents in the abdomen of children and young adults, and EBV is identified in 15-20\% of such lymphomas. In immunodeficiency-associated Burkitt lympho$\mathrm{ma}, \mathrm{EBV}$ is detected in $30-40 \%$ of cases. Most cases of Burkitt lymphoma associated with EBV express EBNA-1 and EBERs [4-10]. The morphology of endemic, sporadic and immunodeficiency-related Burkitt lymphoma is identical, but this last type can appear somewhat more pleomorphic and have plasmacytoid features. In all cases of Burkitt lymphoma, whether EBV is detected or not, translocation of the c-myc oncogene on chromosome 8 is present [22].

Aspirates of Burkitt lymphoma are usually cellular comprising monotonous, intermediate-sized lymphocytes (i.e. with nuclei similar or smaller to those of macrophages) that lie singly. Their nuclei are round-to-oval with well-defined nuclear borders, coarse chromatin and 2-5 small but conspicuous nucleoli per nucleus. Lymphoma cells contain scant to moderate amounts of blue, vacuolated cytoplasm (fig. 2). The vacuoles contain a neutral lipid. These cytoplasmic vacuoles are best appreciated with a Romanowsky stain. Several tingible body macrophages, mitotic figures and apoptosis are often seen [17, 18]. Immunophenotyping of Burkitt lymphoma shows tumor cells that are positive for CD19, CD20, CD79a, CD10, BCL6, CD38 and negative for BCL2, CD5, CD23, and TdT. Ki67 typically shows a high proliferation index (nearly $100 \%$ of cells stain positive). Cytogenetics reveals various $\mathrm{c}-M Y C$ translocations, namely $\mathrm{t}(8 ; 14)$ (q24; $\mathrm{q} 32)$, $\mathrm{t}(8 ; 22)(\mathrm{q} 24 ; \mathrm{q} 11)$ and $\mathrm{t}(2 ; 8)(\mathrm{q} 12 ; \mathrm{q} 24)$ [4-10]. The breakpoints within the c-MYC gene differ between endemic and HIV-related Burkitt lymphoma. MYC translocation is not specific for Burkitt lymphoma, but may also be overexpressed in acute lymphoblastic and myeloid leukemia, DLBCL with an unfavorable prognosis, plasmablastic lymphoma, transformed follicular lymphoma and 'double-hit lymphomas' which have a concurrent IgHBCL2 rearrangement $[23,24]$. The differential diagnosis 
Fig. 2. a Monomorphic population of dyshesive, intermediate-sized, malignant lymphoid cells with round nuclei, finely granular chromatin, small nucleoli and vacuolated cytoplasm consistent with Burkitt lymphoma. Papanicolaou stain, $\times 600$. b Burkitt lymphoma cells with dark blue cytoplasm containing several lipid vacuoles. Diff-Quik stain, $\times 600$.
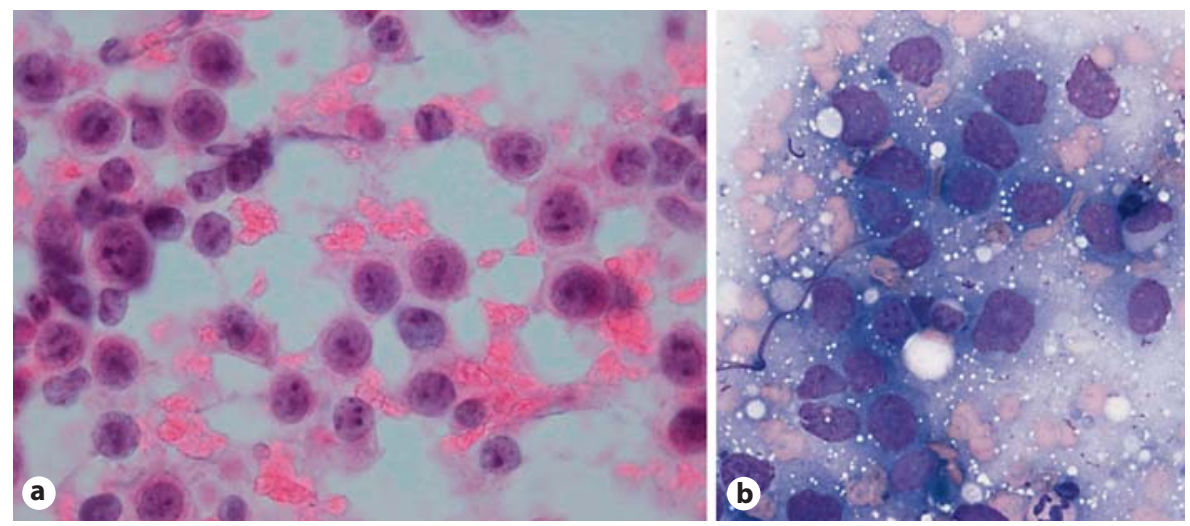

includes other high-grade non-Hodgkin lymphomas (lymphoblastic and plasmablastic), primitive neuroectodermal tumor (PNET)/Ewing tumors and rhabdomyosarcoma. The distinction between DLBCL and Burkitt lymphoma is critical because it implies different treatment. Sometimes this distinction may be very difficult to make on FNA [25]. Burkitt lymphoma has a more monotonous and uniform appearance with more identical, round, nuclei with far fewer nuclear indentations compared to other lymphomas. Ewing sarcoma and PNET have cytoplasmic vacuoles like Burkitt lymphoma, but these tumor cells contain PAS-positive glycogen, not a lipid. In addition, a clustering of cells with nuclear molding is another helpful feature sometimes seen with PNET/ Ewing sarcoma $[17,18]$.

\section{Diffuse Large B Cell Lymphoma}

The etiology of DLBCL, in most cases, remains unknown. However, EBV is associated with several subtypes of DLBCL including EBV-positive DLBCL of the elderly, PEL and PBL.

\section{EBV-Positive DLBCL of the Elderly}

This rare, aggressive lymphoma occurs in patients over 50 years of age and is associated with a decline or senescence in immune function that accompanies ageing [26]. It is more common in Asia than in Western populations and tends to involve extranodal sites (skin, lungs, tonsils or stomach) more frequently than lymph node disease. The prognosis is poor. Although the morphology and immunocytochemistry can be very similar to HIVassociated lymphoproliferative disorders, elderly patients with this EBV-positive DLBCL are usually HIV-negative. These lymphomas may have a diverse cytomorphologic appearance including polymorphous and large cell sub- types, both usually associated with necrosis. Reed-Sternberg-like giant cells may be a prominent feature. There is also a high proliferation index and tumor cells are positive for pan-B cell markers (although CD20 may be lost), variably CD30-positive and demonstrate LMP-1 and EBNA-2 in many cases [27, 28].

\section{Plasmablastic Lymphoma}

PBL is a rare, aggressive lymphoma that usually involves the oral cavity and jaw $[29,30]$. It has also been described in other sites including the anorectum, skin, breast, testes and lymph nodes. It occurs most frequently in HIV-infected patients, but can also occur in those who are HIV-negative [31]. PBL is a distinct subtype of DLBCL that is characterized by an immunoblastic and/or plasmablastic morphology, immunoglobulin heavy-chain gene rearrangement and consistent expression of plasma cell antigens. Two subtypes of PBL may be seen: the oral mucosa type and a type with plasmacytic differentiation. The cytomorphology comprises large monomorphic cells, resembling plasmablasts or immunoblasts [32]. These lymphoma cells have fairly abundant basophilic cytoplasm, eccentrically situated nuclei with single or multiple nucleoli and a paranuclear hof (fig. 3). The specimen is usually cellular with apoptosis, tingible body macrophages and increased mitotic figures. PBL is EBERpositive but LMP-negative. Plasma cell markers including CD138, CD38 and MUM1 are positive, in addition to CD79a, CD30 and EMA. PBL is variably positive or negative for CD45, CD20 and PAX5. The malignant lymphocytes are usually larger and more pleomorphic when compared with plasmacytoma/myeloma [33]. Patients with plasma cell neoplasms often show skeletal lesions, may have paraproteins and are EBV-negative. The differential diagnosis of PBL includes plasmacytoma, poorly 
Fig. 3. a PBL comprising large monomorphic cells with abundant cytoplasm and eccentrically situated nuclei. Diff-Quik stain, $\times 400$. b MUM1 positivity on core biopsy from the same patient.
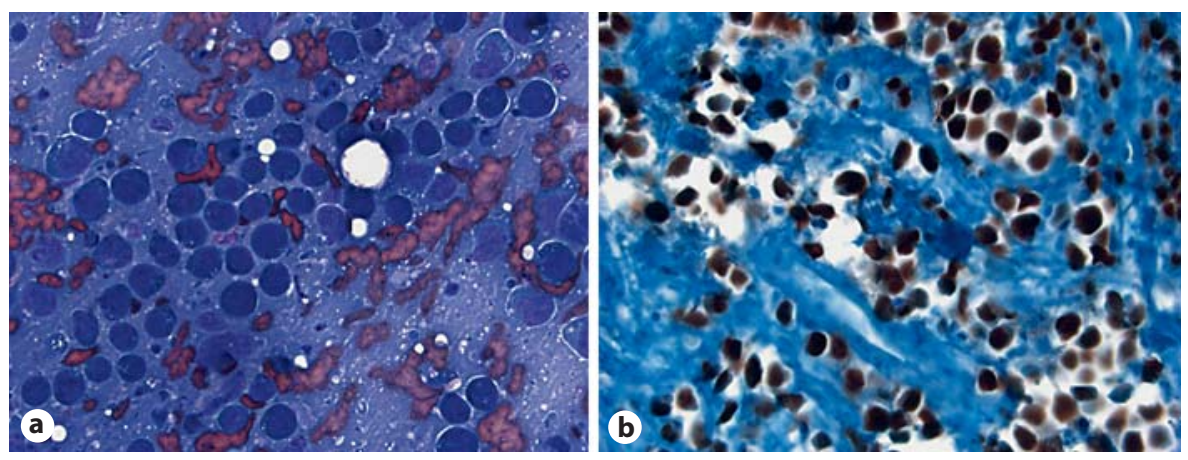

Fig. 4. PEL cells seen in a cytospin preparation from HIV-positive patients. a DiffQuik stain, $\times 200$, courtesy of W.E. Khalbuss from UPMC, Pittsburgh, Pa., USA. b Wright-Giemsa stain, $\times 1,000$.

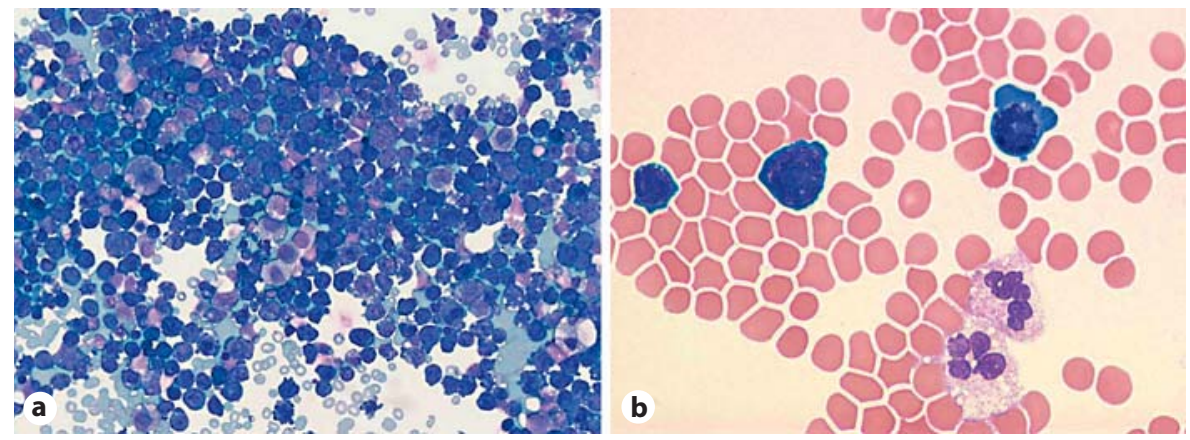

differentiated carcinoma, other large cell lymphomas (e.g. lymphoblastic lymphoma, a plasmablastic variant of Burkitt's lymphoma or a blastoid variant of mantle cell lymphoma), amelanotic melanoma and other undifferentiated neoplasms $[5,7,34-36]$.

\section{Primary Effusion Lymphoma}

PEL classically involves body cavities (pleura, peritoneal, pericardial and, rarely, cerebrospinal fluid or joint spaces). A solid (extracavitary) variant also occurs in which the patient manifests with a solid tumor associated with or subsequently developing a lymphomatous effusion. PEL occurs most commonly in HIV-infected individuals but has, on occasion, been diagnosed in HIV-negative elderly persons. PEL, while strongly associated with human herpesvirus 8 (HHV-8), has a variable association with EBV [37]. The prognosis of PEL is very poor. The cytomorphology varies from large immunoblastic to anaplastic lymphoma tumor cells (fig. 4) [38-40]. ReedSternberg-like cells may also be seen. PEL cells usually lack B cell and $\mathrm{T}$ cell antigens (null cell phenotype) but may express CD30, EMA, plasma cell antigens (CD38, CD138, MUM1) and HHV-8 (LNA-1) [5, 41-43]. The differential diagnosis includes other primary and secondary lymphomatous effusions as well as poorly differentiated neoplasms involving body fluids.

\section{Primary Central Nervous System Lymphoma}

PCNSL (or primary DLBCL of the CNS) may involve the brain, leptomeninges and spinal cord (but not dura), as well as the eyes (so-called primary intraocular lymphoma). In these cases, disease is limited to the CNS. Imaging studies typically reveal a well-defined, enhancing focal lesion. The incidence of PCNSL is markedly increased in HIV-infected patients, but has decreased in this population since the widespread use of highly active antiretroviral therapy in many countries [44]. In immunocompetent patients, EBV is generally absent from PCNSL. However, in the immunocompromised setting, this lymphoma is strongly associated with EBV and tumor cells express almost all of the EBV-latent encoded proteins. The vast majority is of the DLBCL type, which consists of large malignant lymphoid cells with a moderate amount of cytoplasm, large nuclei and conspicuous nucleoli (immunoblastic cytomorphology) (fig. 5). There is often extensive necrosis and intermingled histiocytes, especially in patients treated with high-dose corticosteroids. The B cell markers CD19, CD20 and CD22 are usually expressed in lymphoma cells, and variable positivity may be seen with CD10, BCL6, BCL2 and MUM1. Depending upon the location of the tumor, cytologic evaluation of the cerebrospinal fluid may yield diagnostic cells. Meninges are involved in 25-35\% of AIDS-related PCNSL 
cases. EBV studies (in situ hybridization for EBER in tumor cells and PCR for EBV DNA in CSF), flow cytometry and immunoglobulin heavy-chain PCR are all diagnostically useful $[4,5,45]$. Measurement of EBV DNA within CSF serves as a surrogate marker to monitor therapeutic response.

\section{Posttransplant Lymphoproliferative Disorders}

Patients undergoing organ transplantation and associated immunosuppressive therapy have an increased incidence of developing lymphoproliferative disorders. PTLD comprise several diseases ranging from benign polyclonal lymphoid or plasmacytic hyperplasia to aggressive $\mathrm{B}$ cell/T cell lymphoma or myeloma. The majority $(80 \%)$ of PTLD are associated with EBV. Almost one third of T cell PTLD cases are EBV-negative. PTLD that are EBVnegative tend to occur mainly in adults, develop later than in EBV-positive cases and are usually of the monomorphic type. Absence of EBV in PTLD is considered an adverse prognostic indicator. PTLD usually occur within 1 year of transplantation, but can occur many years thereafter. PTLD may involve lymph nodes and extranodal sites (gastrointestinal tract, lungs, liver and the allograft). Allograft involvement is more common in EBV-associated cases. The finding of EBER-positive cells helps differentiate PTLD from rejection in allografts. To date, there have been limited studies describing the cytopathology of PTLD [46-48]. [49]:

According to the WHO, there are 4 categories of PTLD

- Early lesions involve a heterogeneous population of LMP-1+ immunoblasts, centrocytes and small and medium-sized polytypic B- and T-lymphoid cells. Plasmacytic hyperplasia in these early lesions can be striking; their proliferation is often polyclonal and nodal architecture is typically retained. Early lesions may regress with a reduction of immune suppression.

- Polymorphic PTLD morphologically resemble early lesions, but necrosis and cellular atypia are more commonly seen. Atypical immunoblasts that resemble Reed-Sternberg cells may be encountered. The proliferation in these lesions is monoclonal (which may be focal) and the underlying tissue architecture is often destroyed (fig. 6).

- Monomorphic (i.e. lymphoma-like) PTLD is a destructive disorder containing neoplastic lymphoid cells. These PTLD are classified according to the lymphoma they resemble. The most common lymphoma to occur is DLBCL, but occasionally Burkitt lymphoma, plasma cell myeloma and peripheral $\mathrm{T}$ cell lymphomas are also

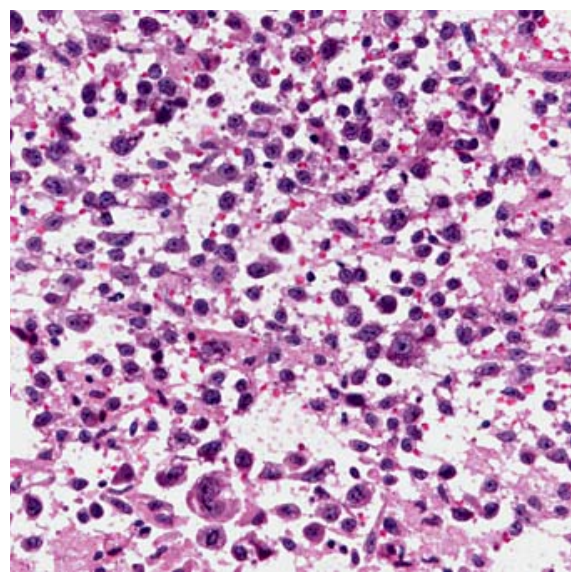

Fig. 5. PCNSL from an AIDS patient showing dyshesive, highly atypical lymphocytes, many with immunoblastic features. H\&E stain, $\times 200$.

encountered [4-6, 9, 36]. Monomorphism does not signify that there is complete cellular monotony, as aspirates may contain pleomorphic Reed-Sternberg-like cells and/or exhibit prominent plasmacytic differentiation. B cell PTLD are usually positive for B cell markers (CD19, CD20, CD79a) and CD30. EBV-positive cases are more likely to have a postgerminal center phenotype (CD10-, BCL6-, MUM1+) whereas EBV-negative cases tend to display a germinal center phenotype (CD10+, BCL6+, MUM1-) (fig. 6).

- Classical Hodgkin lymphoma-type PTLD.

\section{T and NK Cell Lymphomas}

Most EBV-associated lymphoproliferative disorders are of B cell origin, but EBV can also infect CD4+, CD8+ peripheral T cells and NK cells. EBV is associated with several $\mathrm{T}$ cell lymphoproliferative disorders including some peripheral $\mathrm{T}$ cell lymphomas, angioimmunoblastic T cell lymphoma, extranodal nasal NK cell/T cell lymphoma (fig. 6), enteropathy-type T cell lymphoma, hepatosplenic and nonhepatosplenic T cell lymphoma, EBVassociated cutaneous $\mathrm{T}$ cell lymphoproliferative disorders and aggressive NK cell leukemia/lymphoma [4].

Extranodal NK cell/T cell lymphoma (formerly called angiocentric $\mathrm{T}$ cell lymphoma or lethal midline granuloma) is found predominantly in Asia and Central and South America. These lymphomas usually involve the nasal cavity and cause destruction of the midface, palate and orbit. They may also involve skin, soft tissue, testes and the gastrointestinal tract. In disseminated disease, lymph nodes can also be involved. NK cell/T cell lym- 
Fig. 6. a Polymorphic B cell PTLD (LMPpositive) from a lung FNA in a 50-yearold transplant recipient. Diff-Quik stain, $\times 600$; H\&E stain, $\times 400$. b Monomorphic T cell PTLD (EBER-negative) from a lung FNA in a 61-year-old transplant recipient. Diff-Quik stain, $\times 600$; H\&E stain, $\times 400$.

Fig. 7. Lung FNA of an extranodal NK cell/T cell lymphoma, nasal type, showing atypical lymphocytes with Diff-Quik (a) and Papanicolaou (b) stains, $\times 600$. c In situ hybridization in this case demonstrates several EBER-positive malignant lymphocytes. $\times 600$. d Flow cytometry studies of this aspirate show a predominant NK cell/T cell lymphoid population (dark green scatter at the top of the plot) that coexpresses CD7 and CD56.
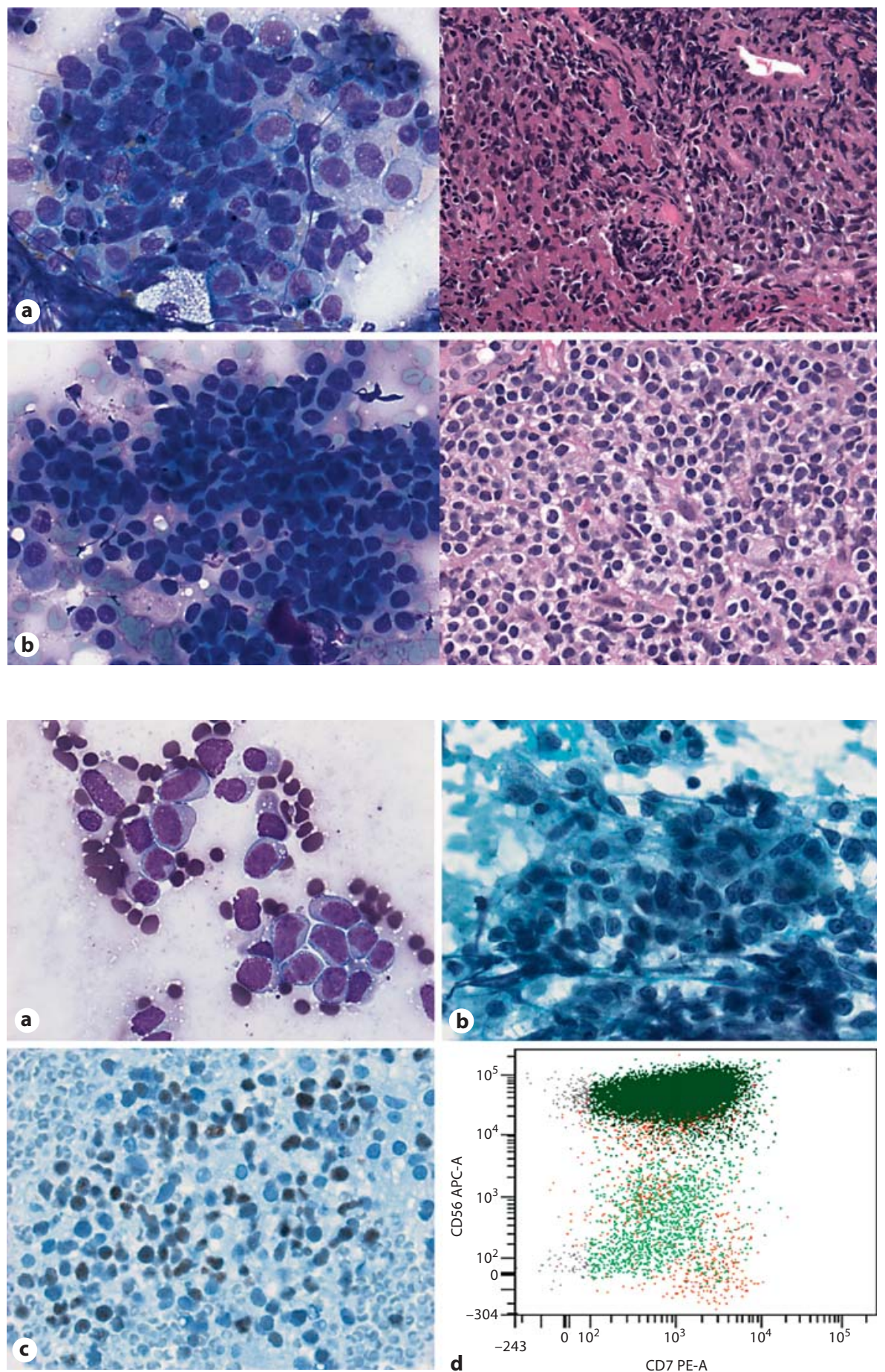

phoma, although rare, is diagnosable on the basis of FNA biopsy alone, especially in view of its distinctive immunophenotype and EBV association [50, 51]. The cytomorphology is typically that of a moderately cellular smear associated with a necrotic background [52] (fig. 7). Ne- crosis is attributed mainly due to vascular occlusion by infiltrating lymphoma cells. Plasma cells, eosinophils, follicular dendritic cells and histiocytes are often seen in the background, while tingible body macrophages are usually absent. The overall cytomorphological appear- 
ance may mimic an inflammatory process rather than that of a lymphoma. Tumor cells may lie singly and in loosely cohesive aggregates. Lymphoid aggregates containing arborizing vessels may be noted. The malignant lymphoid cells may be pleomorphic and vary in size from small to large and may be round to spindle in shape. Some tumors are more monomorphic in appearance. Tumor cell nuclei are eccentrically situated and these cells have variable amounts of blue cytoplasm present. Occasional azurophilic granules may be noted in their cytoplasm. The chromatin is coarse and unevenly distributed, and nucleoli may be indistinct or nuclei may contain several small nucleoli $[4,36,53,54]$.

The differential diagnosis includes B cell non-Hodgkin lymphoma, which is generally more monomorphic in appearance. Given the pleomorphic appearance, carcinoma and melanoma may be confused with extranodal $\mathrm{NK}$ cell/T cell lymphoma. However, carcinoma and melanoma do not usually have a polymorphous background consisting of plasma cells, eosinophils, follicular dendritic cells and histiocytes. Ancillary investigations are usually required to make the correct diagnosis. Extranodal $\mathrm{NK}$ cell/T cell lymphomas are typically positive for CD3 (cytotoxic), CD56, CD2, HLA-DR and cytotxic molecules (granzyme $\mathrm{B}$, TIA1, perforin). They are variably positive for CD7, CD43, CD45RO, CD25 and CD30, but are negative for CD4, CD5, CD8, CD16, CD33, and CD57 [4, 36, $50-54]$. While LMP-1 immunoreactivity may yield variable results, virtually all lymphoma cells should be labeled with EBER when using in situ hybridization.

\section{Lymphomatoid Granulomatosis}

Lymphomatoid granulomatosis is an angiocentric, angiodestructive, extranodal lymphoproliferative disorder that occurs in adults; when seen in children, it usually arises in males who are HIV-infected. The lung is involved in $90 \%$ of cases, but involvement of the CNS, skin, kidney and liver is common. Lymphoid tissue is infrequently involved. Only a few articles have reported the cytological findings of lymphomatoid granulomatosis $[55,56]$. EBV-infected B cells are large and pleomorphic, but are typically admixed with a predominant population of reactive $T$ cells which may mask the pathology. Infiltration of the blood vessels by the tumor cells causes extensive coagulative necrosis, and this, together with granulomas and giant cells, may lead to an erroneous diagnosis of mycobacterial infection, Wegener's granulomatosis or necrotizing sarcoidosis (fig. 8). The B cells are clonal but the $\mathrm{T}$ cells are not. Lesions may progress to EBV-positive DLBCL $[55,56]$.

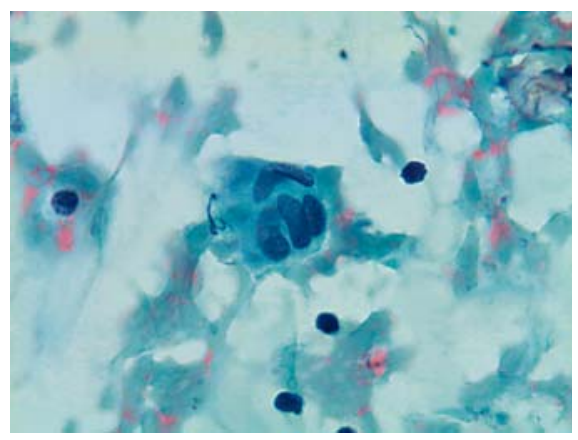

Fig. 8. Epithelioid histiocytes admixed with atypical lymphoid cells in a necrotic background. Further investigations revealed this to be lymphomatoid granulomatosis. Papanicolaou stain, $\times 600$.

\section{EBV-Associated Carcinomas}

EBV is associated with nasopharyngeal carcinoma and lymphoepithelial-like carcinomas of the stomach, liver, salivary glands, lungs, thymus and upper aerodigestive tract [57].

\section{Nasopharyngeal Carcinoma}

There is a high incidence of nasopharyngeal carcinoma in South-East Asia, an intermediate incidence in North Africa and a low incidence in most other parts of the world. Nasopharyngeal carcinomas arise from the mucosal lining of the nasopharynx. EBV has been found in preinvasive nasopharyngeal lesions. Nasopharyngeal brushes and aspirates have been employed to make the diagnosis, but due to limited sensitivity (70-90\%) tissue biopsy is often preferred [58]. Symptoms are often nonspecific and cervical lymphadenopathy, due to metastasizing nasopharyngeal carcinoma, may be the presenting symptom. The WHO classification of nasopharyngeal carcinoma includes [59]:

- Keratinizing squamous cell carcinoma is the most uncommon subtype, found in nonendemic areas. This histological subtype usually affects an older age group and is not associated with EBV. In cytology samples, cohesive clusters and occasional single malignant cells are noted in a background usually devoid of inflammatory cells. Tumor cells have moderate amounts of well-defined keratinized cytoplasm and hyperchromatic nuclei with irregular nuclear borders and coarse chromatin [17, 18, 60-63].

- Nonkeratinizing squamous cell carcinoma (undifferentiated and differentiated) is associated with EBV in- 
Fig. 9. a Differentiated variant of nonkeratinizing nasopharyngeal carcinoma showing a cluster of cells that have a moderate amount of cytoplasm that is keratinized in some cells, large nuclei with vesicular chromatin and prominent nucleoli. Papanicolaou stain, $\times 600$. b Undifferentiated variant of nonkeratinizing nasopharyngeal carcinoma showing bare tumor cell nuclei in a lymphoid background; these nuclei are large, round to oval and have prominent nucleoli. Diff-Quik stain, $\times 400$.
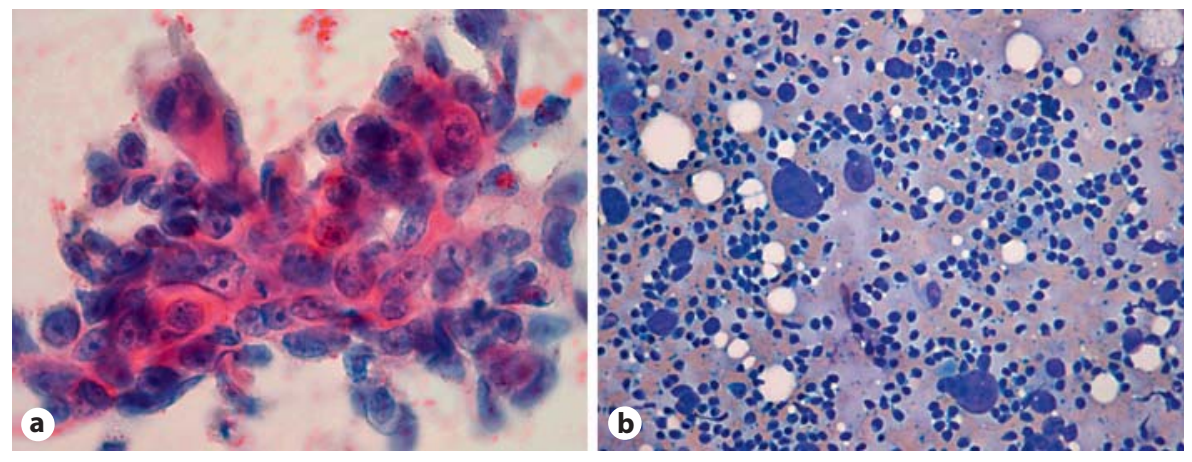

fection $[6,17,18,60-63]$. Almost $100 \%$ of these patients have positive serology against EBV. The differentiated form is the least common $(<15 \%)$ type and undifferentiated tumors are the most common $(>60 \%)$. This subclassification is of no clinical or prognostic significance. FNA specimens of differentiated tumors show cohesive clusters and occasional single cells with moderate amounts of minimally keratinized cytoplasm and round to oval vesicular chromatin present in a background of chronic inflammatory cells (fig. 9). Undifferentiated (lymphoepithelial-like or 'anaplastic') nasopharyngeal carcinomas contain cohesive (syncytial-appearing) clusters and/or single cells present in a background consisting of chronic inflammatory cells. The tumor cell nuclei are round to oval and vesicular with prominent nucleoli, some of which are carrot-shaped and abut on the nuclear membrane. Their cytoplasm is pale and poorly defined and it is not uncommon to find smears with mainly bare nuclei (fig. 9). Some tumors may contain mixed differentiated and undifferentiated areas and tumor cells may rarely assume a spindle cell appearance or contain intracytoplasmic mucin. Occasionally, specimens may be entirely devoid of lymphocytes, show a predominance of plasma cells or eosinophils and even neutrophils, contain necrosis, have epithelioid histiocytes and possibly amyloid granules present. The differential diagnosis includes squamous cell carcinoma, Hodgkin lymphoma, anaplastic large cell lymphoma and germ cell tumor. Reed-Sternberg cells are often binucleated, usually less in number, tend not to be cohesive and contain more abundant cytoplasm than nasopharyngeal carcinoma tumor cells. In anaplastic large cell lymphoma, lymphoid cells are more dispersed than in nasopharyngeal carcinoma, and wreath- and horseshoe-shaped lymphoma cells may sometimes be found. In germ cell tumors, features such as a tigroid background in seminoma and hyaline globules in yolk-sac tumors may assist in the diagnosis $[17,18,62]$.

- Basaloid squamous cell carcinoma resembles similar basaloid tumors that arise in other sites, showing a predominance of basaloid tumor cells that may mimic small cell carcinoma. However, EBER appears to be detectable from cases occurring in the nasopharynx, but not in cases from other sites including the esophagus, larynx, pharynx, hypopharynx and nasal cavity [64]. The cytomorphology of tumors from the nasopharynx has not been characterized $[65,66]$.

Immunocytochemistry, flow cytometry and molecular studies (gene rearrangement) may be required to distinguish between these various entities [17, 18, 61, 62, 67]. With immunocytochemistry, nasopharyngeal carcinoma tumor cells are positive for cytokeratins (pankeratin, CK5/6, 34ßE12, CAM 5.2 and CK19), p63 and EMA (focal), but are negative for CK7, CK20 and CD45. The background shows a mixture of $\mathrm{T}$ and $\mathrm{B}$ lymphocytes. In situ hybridization and/or PCR detects EBV nucleic acid in 75$100 \%$ of nasopharyngeal carcinomas, except for the keratinizing subtype in which the detection of EBV genomes is variable and focal.

\section{Lymphoepithelial-Like Carcinoma of Other Organs}

EBV-associated lymphoepithelial-like carcinoma has been described in the stomach, esophagus, tonsils, salivary glands, thymus and lungs $[57,68,69]$.

$\mathrm{EBV}$ is associated with 2 variants of gastric carcinoma, namely lymphoepithelioma-like (also called gastric carcinoma with lymphoid stroma or medullary carcinoma) and 'ordinary' gastric carcinoma. EBV-associated gastric carcinoma tends to affect the proximal stomach or gastric stump, commonly arises in males, presents at a younger 
Fig. 10. EBV-associated smooth muscle tumor in a pediatric transplant patient. The tumor is cellular and contains fascicles of spindled smooth muscle cells (a; H\&E stain, $\times 200)$ that are strongly EBER positive (b; in situ hybridization; $\times 400)$. Images are courtesy of Sarangarajan Ranganathan, Pittsburgh Children's Hospital, Pa., USA.

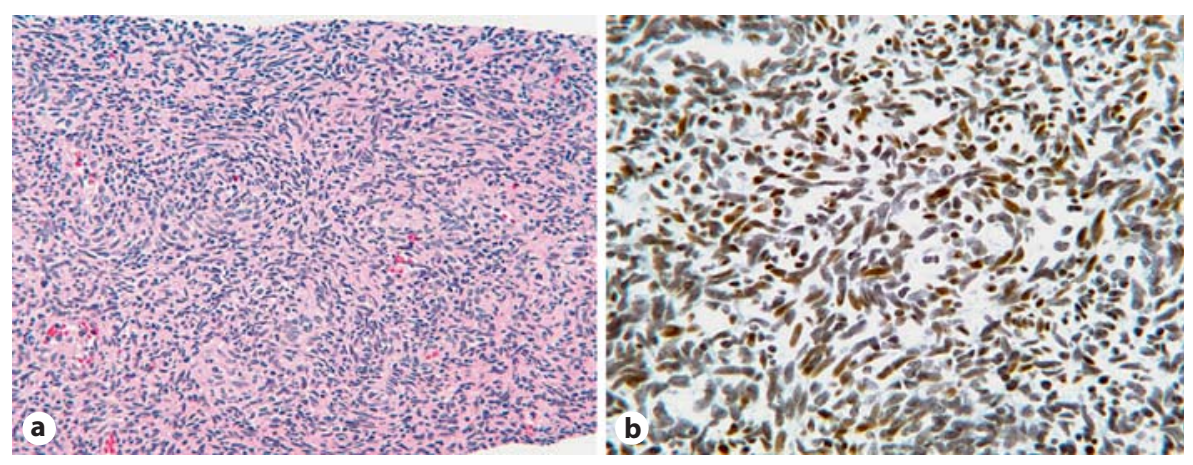

age and has a better prognosis relative to gastric carcinoma not associated with EBV. The interaction between EBV and Helicobacter pylori is currently unknown.

The cytomorphology of EBV-associated gastric carcinoma, to the best of our knowledge, appears not to have been described. However, it is presumed that the lymphoepithelial-like gastric carcinoma would show clusters and singly lying tumor cells with pale cytoplasm, round to oval nuclei, vesicular chromatin and prominent nucleoli present in a background of lymphoid cells, while 'ordinary' gastric carcinoma would demonstrate singly lying malignant cells and clusters, that are cuboidal to columnar in shape with eccentrically situated nuclei showing malignant features, similarly associated with variable numbers of lymphocytes [70,71].

\section{EBV-Associated Mesenchymal Tumors}

EBV is associated with several mesenchymal tumors including EBV-associated smooth muscle tumors, follicular dendritic cell tumors and myopericytomas $[6,57$, 72-74].

\section{EBV-Associated Smooth Muscle Tumors}

EBV smooth muscle tumors (EBV-SMT) encompass benign leiomyomas, smooth muscle tumors of undetermined malignant potential and malignant leimyosarcomas, depending on their morphology and mitotic activity. EBV-SMT have been reported in immunocompromised individuals with HIV infection or following transplantation, especially in children $[72,75]$. They may be multifocal and have been described at many different sites including the dura, liver, lungs, colon, heart, spleen, paravertebral soft tissue, veins, larynx, endobronchus, uterus, gallbladder, CNS and adrenal glands. Their cyto- morphology does not appear to have been described in the literature. However, the histologic evaluation of EBVSMT shows oval to spindle cells with moderate to abundant eosinophilic cytoplasm and nuclear pleomorphism varying from modest to moderate (fig. 10). Also described are occasional small round cells, a hemangiopericytictype architecture and intratumoral T lymphocytes [72, 74]. EBER, EBNA and high copy numbers of EBV can usually be demonstrated in tumor cells, in addition to smooth muscle markers with immunostaining [72]. Other spindle cell lesions including peripheral nerve sheath tumors, dermatofibrosarcoma protuberans, fibrosarcoma, gastrointestinal stromal tumor and mycobacterial spindle cell pseudotumor form part of the differential diagnosis [73].

\section{Follicular Dendritic Cell Tumor}

This is a rare low-grade sarcoma of follicular dendritic cells. The most common site of involvement is the cervical lymph nodes, but this tumor may also occur in lymph nodes from the axilla, mediastinum and retroperitoneum, as well as at extranodal sites such as the tonsils, spleen, gastrointestinal tract, liver and skin. EBV is associated with follicular dendritic cell tumor in $30 \%$ of cases [57]. Most patients present with a painless, slow-growing mass, but occasionally they may manifest with systemic symptoms such as weight loss, fever, lethargy and abdominal pain. Follicular dendritic cell tumors occur in association with Castleman disease in $10-20 \%$ of cases and with inflammatory pseudotumor of the liver.

These tumors have a wide variety of growth patterns including sheets, syncytia, fascicles and singly lying neoplastic cells. Tumor cells may be oval to spindle and contain moderate amounts of cytoplasm, finely granular or vesicular chromatin, intranuclear inclusions and small but distinct nucleoli (fig. 11). Multinucleated cells akin to 
Fig. 11. Follicular dendritic cell sarcoma comprised of fascicles and sheets of spindle cells with moderate amounts of cytoplasm, finely granular chromatin and small nucleoli. Papanicolaou stain, $\times 200$ (a); $\times 400$ (b).

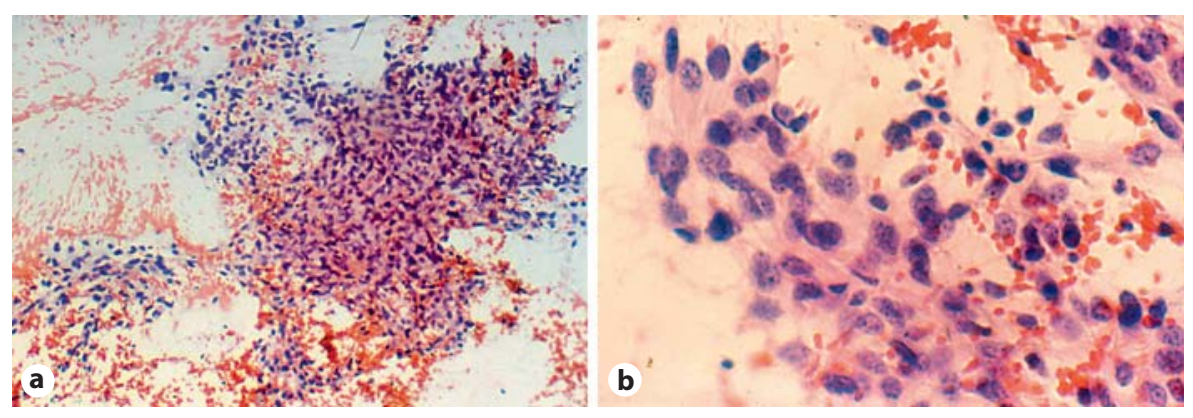

Reed-Sternberg cells can be seen. In general, tumor cells are usually bland, but more atypical forms can be noted. The background aspirate may contain a chronic inflammatory cell infiltrate. The differential diagnosis includes Castleman disease, Hodgkin lymphoma, metastatic carcinoma, gastrointestinal stromal tumor, melanoma, meningioma and inflammatory pseudotumor. In Castleman disease, there may be a predominance of plasma cells, and lymphocytes are likely to demonstrate LNA-1 (HHV-8) positivity in the setting of HIV infection. However, as follicular dendritic cell tumors may occur together with Castleman disease, this distinction can be difficult. Follicular dendritic cell tumors are positive for CD21 (to which EBV binds), CD35, CD23, vimentin, fascin, EMA and clusterin, and are variably positive for CD45, S100, CD68, CD1a, muscle specific actin, cytokeratin and vascular markers $[36,57,74,76,77]$.

\section{Myopericytoma}

This is a rare, benign, mesenchymal tumor that usually arises in subcutaneous and soft tissues. The tumor is composed of pericytic cells demonstrating myoid differentiation. In HIV-negative patients, myopericytoma is situated mainly in somatic soft tissue and presents as an isolated, painless, slow-growing mass. In the HIV-infected patient, myopericytoma presents in various locations such as the bronchi, vocal cords, tongue, brain, spinal cord and liver, and these tumors are often multifocal. They are distinct from EBV-SMT in their morphology and immunocy tochemistry. Examined histologically, the tumor consists of round to spindled myoid cells with a concentric growth pattern centered around small blood vessels. Immunocytochemistry reveals that myopericytomas are positive for smooth muscle actin, caldesmon and CD34, and negative for desmin, cytokeratin, S100, HMB-45 and CD31. Tumor cells are positive for EBER, unlike perimyocytoma that occurs in HIV-negative patients. The differential diagnosis includes EBV-SMT, an- gioleimyoma and myofibroma [78, 79]. The cytomorphology of myopericytoma is not well characterized, but would consist of concentrically arranged nests of plump spindle cells and vascular channels [80].

\section{Conclusion}

It is estimated that $18 \%$ of malignancies in humans are due to infectious organisms, $1 \%$ of which are attributable to EBV [3]. EBV is linked to various neoplastic disorders including lymphoproliferative, epithelial and mesenchymal tumors. Cytological evaluation of these neoplasms in conjunction with the prudent use of ancillary investigations, including the detection of underlying EBV infection in the host/and or tumor cells, will allow the majority of EBV-associated malignancies to be accurately diagnosed in cytology samples. Initially, it was believed that diagnostic information regarding the prognosis and treatment of EBV-associated malignancies was more dependent upon the accurate morphological classification of these tumors than on whether EBV was identified. However, more recent work has begun to focus on the success of EBV immunotherapy (e.g. antiviral cytotoxic T cells) in EBV-associated malignant diseases [81].

References

1 Unger E, Purtilo DT: Epstein-Barr virus and human diseases; in Connor DH, Chandler FW, Manz HJ, et al (eds): Pathology of Infectious Diseases. Stamford, Appleton \& Lange, 1997, vol 1, pp 113-123.

2 Johannsen EC, Kaye KM: Epstein-Barr virus (infectious mononucleosis, Epstein-Barr virus-associated malignant diseases, and other diseases); in Mandell GL, Bennett JE, Dolin R (eds): Mandell, Douglas, and Bennett's Principles and Practice of Infectious Diseases, ed 7. Philadelphia, Elsevier, 2010, pp 1989-2010. 
-3 Parkin D: The global health burden of infection-associated cancers in the year 2002. Int J Cancer 2006;118:3030-3044.

4 Carbone A, Gloghini A, Dotti G: EBV-associated lymphoproliferative disorders: classification and treatment. Oncologist 2008;13: 577-585.

5 Rezk S, Weiss L: Epstein-Barr virus-associated lymphoproliferative disorders. Hum Pathol 2007:38:1293-1304.

-6 Delecluse H, Feederle R, O’Sullivan B, Taniere P: Epstein-Barr virus-associated tumors: an update for the attention of the working pathologist. J Clin Pathol 2007;60: 1358-1364.

7 Gulley M, Tang W: Laboratory assays for Epstein-Barr related disease. J Mol Diagn 2008; 10:279-292.

8 Naresh K: Lymphoproliferative disorders in the immunosuppressed. Diagn Histopathol 2009;16:206-215

-9 Tran H, Nourse J, Hall S, Green M, Griffiths L, Gandhi M: Immunodeficiency-associated lymphomas. Blood Rev 2008;22:261-281.

$\checkmark 10$ Hecht J, Cibas E, Kutok J: Fine-needle aspiration cytology of lymphoproliferative disorders in the immunosuppressed patient: the diagnostic utility of is situ hybridization for Epstein-Barr virus. Diagn Cytopathol 2002; 26:360-365.

11 Epstein MA, Achong BG, Barr YM: Virus particles in cultured lymphoblasts from Burkitt's lymphoma. Lancet 1964;:702-703.

12 Pantanowitz L, Leiman G, Garcia L: Microbiology; in Pantanowitz L, Michelow P, Khalbuss WE (eds): Cytopathology of Infectious Diseases. New York, Springer, in press.

13 Gulley ML, Glaser SL, Craig FE, Borowitz M, Mann RB, Shema SJ, Ambinder RF: Guidelines for interpreting EBER in situ hybridization and LMP1 immunohistochemical tests for detecting Epstein-Barr virus in Hodgkin lymphoma. Am J Clin Pathol 2002;117:259267.

14 Cohen JI: Epstein-Barr virus infection. N Engl J Med 2000;343:481-492.

15 Thorley-Lawson DA, Gross A: Persistence of the Epstein-Barr virus and the origins of associated lymphomas. N Engl J Med 2004; 350:1328-1337.

16 Das DK, Francis IM, Sharma PN, Sathar SA, John B, George SS, Mallik MK, Sheikh ZA, Haji BE, Pathan SK, Madda JP, Mirza K, Ahmed MS, Junaid TA: Hodgkin's lymphoma: diagnostic difficulties in fine-needle aspiration cytology. Diagn Cytopathol 2009; 37:564-573

17 Cibas E, Ducatman B (eds): Cytology: Diagnostic Principles and Clinical Correlates, ed 3. Philadelphia, Saunders Elsevier, 2009.

18 Sidawy M, Syed A (eds): Fine Needle Aspiration Cytology. Philadelphia, Churchill Livingstone Elsevier, 2007.
19 Iacobuzio-Donahue CA, Clark DP, Ali SZ: Reed-Sternberg-like cells in lymph node aspirates in the absence of Hodgkin's disease: pathologic significance and differential diagnosis. Diagn Cytopathol 2002;27:335-339.

20 Walts AE: Fine-needle aspiration of extranodal Hodgkin's lymphoma misinterpreted as carcinoma. Diagn Cytopathol 2009;37: 313-314

21 Kolonić SO, Prasek-Kudrna K, Roso V, Radić-Kristo D, Planinc-Peraica A, Dzebro S, Kardum-Skelin I, Jaksić B: Value of fineneedle aspiration cytology in diagnosis of Hodgkin's lymphoma and anaplastic large cell lymphoma: one centre experience. Coll Antropol 2010;34:75-79.

22 Stelow EB, Policarpio-Nicolas ML, Sudduth KW, LeGallo RD: Burkitt lymphoma. Diagn Cytopathol 2008;36:172-173.

23 Troxell ML, Bangs CD, Cherry AM, Natkunam Y, Kong CS: Cytologic diagnosis of Burkitt lymphoma. Cancer 2005;105:310318.

24 Slack GW, Gascoyne RD: MYC and aggressive B-cell lymphomas. Adv Anat Pathol 2011;18:219-228.

25 Ali AE, Morgen EK, Geddie WR, Boerner SL, Massey C, Bailey DJ, da Cunha Santos G: Classifying B-cell non-Hodgkin lymphoma by using MIB-1 proliferative index in fineneedle aspirates. Cancer Cytopathol 2010; 118:166-172.

26 Adam P, Bonzheim I, Fend F, QuintanillaMartínez L: Epstein-Barr virus-positive diffuse large B-cell lymphomas of the elderly. Adv Anat Pathol 2011;18:349-355.

27 Shimoyama Y, Asano N, Kojima M, Morishima S, Yamamoto K, Oyama T, et al: Age-related EBV-associated B-cell lymphoproliferative disorders: diagnostic approach to a newly recognised clinicopathologic entity. Pathol Int 2009;59:835-843.

-28 Shimoyama Y, Yamamoto K, Asano N, Oyama T, Kinoshita T, Nakamura S: Age-related Epstein-Barr virus associated B-cell lymphoproliferative disorders: special reference to lymphomas surrounding this newly recognised clinicopathologic disease. Cancer Sci 2008;99:1085-1091.

29 Pantanowitz L, Carbone A, Dezube BJ: Historical perspective of plasmablastic lymphoma; in Castillo JJ (ed): Plasmablastic Lymphoma. An Emergent Disease with Poor Prognosis. Saarbrücken, VDM Verlag Dr. Muller, 2010, pp 3-15.

30 Pantanowitz L, Dezube BJ: Editorial comment: plasmablastic lymphoma - a diagnostic and therapeutic puzzle. AIDS Read 2007; 17:448-449.

31 Castillo J, Pantanowitz L, Dezube BJ: HIVassociated plasmablastic lymphoma: lessons learned from 112 published cases. Am J Hematol 2008;83:804-809.

-32 Lin O, Gerhard R, Zerbini MC, Teruya-Feldstein J: Cytologic features of plasmablastic lymphoma. Cancer 2005;105:139-144.
33 Pantanowitz L, Pihan G, Carbone A, Dezube BJ: Differentiating HIV-associated nonHodgkin's lymphomas with similar plasmacellular differentiation. J HIV Ther 2009; 14: 24-33.

34 Wang J, Hernandez O, Sen F: Plasmablastic lymphoma involving breast: a case diagnosed by fine-needle aspiration and core needle biopsy. Acta Cytopathol 2008;36:257261.

35 Raviele P, Pruneri G, Maiorano E: Plasmablastic lymphoma: a review. Oral Dis 2009; 15:38-45.

36 Skoog L, Tani E: FNA cytology in the diagnosis of lymphoma; in SR Orell (ed): Monographs in Clinical Cytology. Basel, Karger, 2009

37 Mack AA, Sugden B: EBV is necessary for proliferation of dually infected primary effusion lymphoma cells. Cancer Res 2008;68: 6963-6968.

38 Brimo F, Popradi G, Michel RP, Auger M: Primary effusion lymphoma involving three body cavities. Cytojournal 2009;6:21.

39 Moatamed NA, Song SX, Apple SK, Said JW: Primary effusion lymphoma involving the cerebrospinal fluid. Diagn Cytopathol 2011, E-pub ahead of print.

40 Lang TU, Khalbuss WE, Monaco SE, Michelow P, Pantanowitz L: review of HIV-related cytopathology. Patholog Res Int 2011;2011: 256083.

41 Afessa B: Pleural effusions and pneumothoraces in AIDS. Curr Opin Pulm Med 2001;7: 202-209.

42 Sullivan R, Pantanowitz L, Casper C, Stebbing J, Dezube B: Epidemiology, pathophysiology and treatment of Kaposi sarcomaassociated herpes-virus disease: Kaposi sarcoma, primary effusion lymphoma and multicentric Castleman disease. Clin Infect Dis 2008;47:1209-1215.

43 Patel M, Michelow P, Philip V, Patel P, Ameen O, Allard U, Heard V: AIDS-related primary effusion of the pleural cavity: a case report. South Afr J Epidemiol Infect 1999; 14:49-51.

44 Aboulafia DM, Pantanowitz L, Dezube BJ: AIDS-related non-Hodgkin lymphoma: still a problem in the era of HAART. AIDS Read 2004; $14: 605-617$

45 Gerstner E, Batchelor T: Primary nervous system lymphoma. Arch Neurol 2010;67: 291-297.

-46 Ohori NP, Whisnant RE, Nalesnik MA, Swerdlow SH: Primary pleural effusion posttransplant lymphoproliferative disorder: distinction from secondary involvement and effusion lymphoma. Diagn Cytopathol 2001; 25:50-53.

47 Davey DD, Gulley ML, Walker WP, Zaleski S: Cytologic findings in posttransplant lymphoproliferative disease. Acta Cytol 1990;34: 304-310. 
48 Dusenbery D, Nalesnik MA, Locker J, Swerdlow SH: Cytologic features of posttransplant lymphoproliferative disorder. Diagn Cytopathol1997;16:489-496.

49 Swerdlow SH, Webber SA, Chadburn A, Ferry JA: Post-transplant lymphoproliferative disorder; in Swerdlow SH, Campo E, Harries $\mathrm{NL}$, et al (eds): WHO Classification of Tumours of Haematopoietic and Lymphoid Tissues. Lyon, IARC, 2008, pp 343-349.

-50 Ng WK, Lee CY, Li AS, Cheung LK: Nodal presentation of nasal-type NK/T-cell lymphoma: report of two cases with fine needle aspiration cytology findings. Acta Cytol 2003;47:1063-1068.

-51 Cho EY, Gong G, Khang SK, Kang YK, Huh J: Fine needle aspiration cytology of CD56positive natural killer/T-cell lymphoma of soft tissue. Cancer 2002;96:344-350.

- 52 Kishimoto K, Kitamura T, Hirayama Y, Tate G, Mitsuya T: Three cases of extranodal NK/ T-cell lymphoma of the nasal type diagnosed by nasal brush cytology. Diagn Cytopathol 2007;35:125-129.

-53 Gerstner E, Batchelor T: Primary nervous system lymphoma. Arch Neurol 2010;67: 291-297.

54 Galindo L, Garcia F, Hanau C, Lessin S, Jhala N, Bigler R, et al: Fine needle aspiration biopsy in the evaluation of lymphadenopathy associated with cutaneous T-cell lymphoma (mycosis fungoides/ Sezary syndrome). Am J Clin Pathol 2000;113:865-871.

55 Williams WL, Clark DA, Saiers JH: Fine needle aspiration diagnosis of lymphomatoid granulomatosis: a case report. Acta Cytol 1992;36:91-94.

- 56 Vargas J, Arguelles M, Nevado M, de la Serna J, de Agustín P: Fine needle aspiration biopsy of a cutaneous relapse of lymphomatoid granulomatosis: a case report. Acta Cytol 1993;37:205-208.

-57 Deyrup A: Epstein-Barr virus-associated epithelial and mesenchymal neoplasms. Human Pathol 2008;39:473-483.

58 Chang AR, Liang XM, Chan AT, et al: The use of brush cytology and directed biopsies for the detection of nasopharyngeal carcinoma and precursor lesions. Head Neck 2001; 23:637-645.
59 Chan JKC, Bray F, McCarron P, et al: Nasopharyngeal carcinoma; in Barnes L, Eveson JW, Reichart P, Sidransky D (eds): World Health Organization Classification of Tumours - Pathology and Genetics of Head and Neck Tumours. Lyon, IARC Press, 2005, pp 85-97.

60 Brennan B: Nasopharyngeal carcinoma. Orphanet J Rare Dis 2006;1:23.

61 Kollur S, El Haq I: Fine-needle aspiration cytology of metastatic nasopharyngeal carcinoma in cervical lymph nodes: comparison with metastatic squamous-cell carcinoma, and Hodgkin's and non-Hodgkin's lymphoma. Diagn Cytopathol 2003;28:18-22.

62 Orell S, Sterret G, Whitaker D: Fine Needle Aspiration Cytology, ed 4. Philadelphia, Elsevier Churchill Livingstone, 2005.

63 Hanji D, Shujing S, Shuwei H, Gohao L: The cytological diagnosis of nasopharyngeal carcinoma from exfoliated cells collected by suction method. An eight-year experience. J Laryngol Otol 1983;97:727-734.

64 Wan SK, Chan JK, Lau WH, Yip TT: Basaloid-squamous carcinoma of the nasopharynx. An Epstein-Barr virus-associated neoplasm compared with morphologically identical tumors occurring in other sites. Cancer 1995;76:1689-1693.

65 Banks ER, Frierson HF Jr, Covell JL: Fine needle aspiration cytologic findings in metastatic basaloid squamous cell carcinoma of the head and neck. Acta Cytol 1992;36:126131.

66 Gilcrease MZ, Guzman-Paz M: Fine-needle aspiration of basaloid squamous carcinoma: a case report with review of differential diagnostic considerations. Diagn Cytopathol 1998;19:210-215.

67 Smith SS, Fowler LJ, Hausenfluke L, Cho CG, Eagan PA, Gulley ML: Diagnosis of EpsteinBarr virus associated nasopharyngeal carcinoma using fine-needle aspiration biopsy and molecular diagnostics. Diagn Cytopathol 1995;13:155-159.

68 Pattle S, Farrell P: The role of Epstein-Barr virus in cancer. Expert Opin Biol Ther 2006; 6:1193-1205.

69 Shah K, Young L: Epstein-Barr virus and carcinogenesis: beyond Burkitt's lymphoma. Clin Microbiol Infect 2009;15:982-988.

70 Uozaki H, Fukayama M: Epstein-Barr virus and gastric carcinoma. Int J Clin Exp Pathol 2008;1:198-216.
71 Fukayama M, Hino R, Uozaki H: EpsteinBarr virus and gastric carcinoma: virus-host interactions leading to carcinoma. Cancer Sci 2008;99:1726-1733.

72 Purgina B, Rao U, Miettinen M, Pantanowitz L: AIDS-related EBV-associated smooth muscle tumors: a review of 64 published cases. Patholog Res Int 2011;10:561548.

-73 Pantanowitz L, Kuperman M, Goulart R: Clinical history of HIV infection may be misleading in cytopathology. Cytojournal 2010;7:7.

74 Deyrup A, Lee V, Hill C, Cheuk W, Toh H, Kesavan S, et al: Epstein-Barr virus-associated smooth muscle tumors are distinctive mesenchymal tumors reflecting multiple infection events: a clinicopathologic and molecular analysis of 29 tumors from 19 patients. Am J Surg Pathol 2006;30:75-82.

75 Lee ES, Locker J, Nalesnik M, Reyes J, Jaffe R, Alashari M, Nour B, Tzakis A, Dickman PS: The association of Epstein-Barr virus with smooth-muscle tumors occurring after organ transplantation. N Engl J Med 1995; 332:19-25.

76 Wright C, Nayler S, Leiman G: Cytopathology of follicular dendritic cell tumors. Diagn Cytopathol 1997;17:138-142.

-77 Guiter G, Sanchez-Marull R, Sapia S, Zakowski M, Gamboni M: Fine-needle aspiration of a follicular dendritic-cell tumor: report of a case and review of the literature. Diagn Cytopathol 2000;22:238-242.

78 Lau P, Wong O, Liu P, Cheung O, Cheung L, Wong W, et al: Myopericytoma in patients with AIDS: a new class of Epstein-Barr virusassociated tumor. Am J Surg Pathol 2009;33: 1666-1672.

79 Dray M, McCarthy S, Palmer A, Bonar S, Stalley P, Marioniemi V, et al: Myopericytoma: a unifying term for a spectrum of tumours that show overlapping features with myofibroma. A review of 14 cases. J Clin Pathol 2006;59:67-73.

80 Rho B, Lee S, Kwon S: Myopericytoma of the neck: sonographic appearance and sonographically guided needle biopsy. J Clin Ultrasound, 2011;39:469-472.

81 Comito MA, Sun Q, Lucas KG: Immunotherapy for Epstein-Barr virus-associated tumors. Leuk Lymphoma 2004;45:19811987. 